\title{
Spatial and Temporal RF Electromagnetic Field Exposure of Children and Adults in Indoor Micro Environments in Belgium And Greece
}

\author{
Günter Vermeeren ${ }^{1}$, Ioannis Markakis ${ }^{2,3}$, Francis Goeminne ${ }^{1}$, Theodoros Samaras ${ }^{2}$, Luc \\ Martens $^{1}$, Wout Joseph ${ }^{1 \text { * }}$
}

July 2013

\begin{abstract}
Personal radio frequency electromagnetic field (RF-EMF) exposure, or exposimetry, is gaining importance in the bioelectromagnetics community but only limited data on personal exposure is available in indoor areas, namely schools, crèches, homes, and offices. Most studies are focused on adult exposure, whereas indoor microenvironments, where children are exposed, are usually not considered. In our study, a method to assess spatial and temporal indoor exposure of children and adults is proposed without involving the subjects themselves. Moreover, maximal possible daily exposure is estimated by combining instantaneous spatial and temporal exposure. In Belgium and Greece, the exposure is measured at 153 positions spread over 55 indoor microenvironments with spectral equipment. In addition, personal exposimeters (which measure the EMF exposure of people wearing them during their daily activities) captured the temporal exposure variations during several days up to one week at 98 positions. The data were analyzed using the robust regression on order statistics (ROS) method to account for data below the detection limit. All instantaneous and maximal exposures satisfied international exposure limits and were of the same order of magnitude in Greece and Belgium. Mobile telecommunications and radio broadcasting (FM) were most present. In Belgium, digital cordless phone (DECT) exposure was present for at least $75 \%$ in all the indoor microenvironments except for schools. Temporal variations of the exposure were mainly due to variations of mobile telecommunication signals. The exposure was higher during daytime than at night due to the increased voice and data traffic on the networks. Total exposure varied the most in Belgian crèches (39.3\%) and Greek homes (58.2\%).
\end{abstract}

\section{Introduction}

*1Department of Information Technology, Ghent University / iMinds Gaston Crommenlaan 8, B-9050 Ghent, Belgium; 2Radiocommunications Laboratory, Department of Physics, Aristotle University of Thessaloniki, GR-54124 Thessaloniki, Greece; 3THESS S.A. Thessaloniki Software Solution S.A. 57001- Pylaia Thessaloniki, Greece

${ }^{\dagger}$ Corresponding author: Prof. Wout Joseph, Ph. D. Ghent University/iMinds Gaston Crommenlaan 8 box 201 B-9050 Gent BELGIUM email:wout.joseph@intec.UGent.be tel: +3293314918 fax: +3293314899.

${ }^{\ddagger}$ Key Words- RF exposure; personal exposure; indoor; child exposure; radio frequency electromagnetic fields (RFEMF); personal exposure meter.
Electromagnetic field exposure of the general public is nowadays assessed with narrowband equipment and personal exposure meters (exposimeters). Very little is known about radio frequency electromagnetic field (RF-EMF) exposure in everyday life in indoor environments such as schools, crèches, homes, and offices. In the last few years, research focus was on exposures in outdoor environments (urban and rural) such as public transportation, cars, and few about offices and homes (Frei et al., 2009; Joseph et al., 2008, 2010, 2012; Thuróczy et 
al., 2008; Viel et al., 2009). Röösli et al. (2010) and Mann (2010) discuss measurement protocols for exposimeters. Personal exposimeters are devices worn on the body. These register the electric fields in the presence of the subject that wears the device. Exposimeters are calibrated in free space and their accuracy strongly depends on the position on the body, given that multipath fading combined with shadowing by the human body result in large field variations for varying measurement positions (Thielens et al. 2013). Almost never child exposure is considered, moreover indoor data for schools, crèches, homes, and offices are mostly lacking. In Tomitsch et al. (2010) exposures in bedrooms of residences are investigated. Only in Juhasz et al. (2011), personal exposure of employees of schools and crèches is considered. Moreover, temporal exposure variations are almost not considered in the literature. Only Joseph et al. 2009, Joseph and Verloock (2010), Mahfouz et al. (2011), and Manassas et al (2012) contribute to temporal data but are not based on personal exposimetry.

Juhasz et al. (2011) reported that child exposures are comparable to the worktime exposure of adults. As stated in Juhasz et al (2011), difficulties arise when involving children in personal exposimetry such as the need for consent of parents, cooperation during longer periods, possible lack of self discipline to follow procedures, and increased risk on breaking equipment. Our paper builds on this idea that experiments with children are difficult, and assesses temporal and spatial child exposure without involving them.

In this paper, spatial and temporal RF exposure is assessed in Belgian and Greek schools, crèches, offices, and homes in different environments (rural, suburban, urban and urban dense). In Belgium and Greece, exposimeter and narrowband measurements with spectrum analyzers are performed at in total 55 indoor location (schools, crèches, offices, and homes). At every indoor location, zones and rooms of maximal exposure were considered.

The objective of this paper is to present a method to assess spatial and temporal indoor exposure of children and adults without involving them. Moreover, extrapolation of spatial exposure to maximal daily exposure is performed by combining instantaneous spatial exposure and temporal exposure. In particular, three objectives are of interest, namely (i) to assess RF exposure in typical indoor mi- croenvironments and also where children are often present, by performing spatial, instantaneous narrowband measurements with a spectrum analyzer, (ii) to characterize the evolution of RF signals during 24 hours in different indoor microenvironments and in various environments, by assessing temporal variations with exposimeters, and (iii) to extrapolate the maximum field values using the instantaneous narrowband measurements and a scale factor calculated from the temporal measurements.

\section{Materials and methods}

\section{Indoor microenvironments and envi- ronments}

The investigated "indoor microenvironments" were homes, schools, crèches, and working offices. The considered "environments" were rural, suburban, urban and dense urban environments. In Belgium, measurements were performed at 29 indoor locations ( 10 schools, 11 crèches, 3 offices and 5 homes) and in Greece at 26 indoor locations ( 5 schools, 10 homes with babies and pre-school children, 5 offices and 6 homes). These indoor environments were located in four different environments (urban, urban dense, suburban, and rural) categorized based on population density and the expected amount and time of traffic (Joseph et al., 2009, Joseph and Verloock 2010). Table 1 summarizes the number of measurement positions per microenvironment and per environment.

For the spatial measurements, a total number of 116 and 36 narrowband measurements were performed in Belgium and Greece, respectively. Per indoor microenvironment temporal exposimeter measurements were carried out in at least one room. In Belgium, also temporal exposimeter measurements occurred in a second room. For schools, a classroom for children between 6-12 years and a classroom for pre-school children (3 to 6 years) were considered. In Greece the selected classrooms were either for children from 6-12 years old or for junior highschool children (13-15 years). Furthermore, in Greece, measurements were performed in teachers' room where indoor sources (such as DECT devices) are usually installed. For crèches, the bedroom of the baby's and infants (below 3 years) and the playing room or zone with highest exposure were con- 
Table 1: Number of spatial- and temporal measurement positions and number of captured samples, per microenvironment and per environment.

\begin{tabular}{lllll}
\hline & Belgium & Greece \\
\cline { 2 - 4 } & $\begin{array}{l}\text { Spatial } \\
\text { \#Positions }\end{array}$ & $\begin{array}{l}\text { Temporal } \\
\text { \#Positions }\end{array}$ & $\begin{array}{l}\text { Spatial } \\
\text { \#Positions }\end{array}$ & $\begin{array}{c}\text { Temporal } \\
\text { \#Positions }\end{array}$ \\
\hline Indoor micro environments & & & & 8 \\
Schools & 40 & 20 & 8 & 8 \\
Crèches / Homes with babies and pre-school children & 44 & 22 & 13 & 13 \\
Offices & 12 & 6 & 6 & 9 \\
Homes & 20 & 10 & 10 & 10 \\
\hline Environments & & & & - \\
Rural & 16 & 8 & - & 9 \\
Suburban & 36 & 18 & 8 & 10 \\
Urban & 64 & 32 & 10 & 21 \\
Urban dense & - & - & 19 & \\
\hline
\end{tabular}

\#Positions = number of measurement positions.

\#Samples = average number of samples per microenvironment.

sidered. For homes, the bedroom and rooms were considered where $\mathrm{WiFi}$ access points are most often located or rooms with the highest exposure. In working offices, typical offices and zones of highest exposure (at least 2 places in each office building) were considered.

\section{Measurement equipment methodology}

and

The measurement procedure for spatial and temporal measurements was as follows. At every location, broadband, frequency-selective (narrowband) and exposimeter measurements are performed in two rooms. The broadband and narrowband measurements were performed during daytime on weekdays. The measurements in the two countries occurred following a joint protocol namely, first scanning the area with broadband probes, followed by accurate small band measurements: the settings of the equipment were the same. Finally, exposimeters were placed standing alone in e.g., class rooms during a week to assess temporal variations of exposure. So, study design was performed jointly and very similar.

\section{Temporal measurements}

The temporal measurements were performed with two types of exposimeters. In Belgium, the EME
SPY 140 (ES 140) is was used, whereas in Greece both the EME SPY 140 and the EME SPY 121 (ES 121) were used. Both exposimeters are manufactured by SATIMO (SATIMO, Courtaboeuf, France). Exposimeters are typically used to quantify personal exposure. The exposimeter ES 140 differs in two ways with respect to ES 121. Firstly, ES 140 measures the exposure in 14 separate frequency bands instead of the 12 bands of ES 121 . Secondly, the detection limit of ES 140 has been reduced and is frequency dependent. The frequency bands together with their corresponding detection limits are listed in Table 2 for both exposimeters. The abbreviations of the various signals are explained below Table 2 .

The measurement procedure in a room started with placing and switching on the exposimeter in the room. The exposimeters recorded the exposure at its position during a whole week. The exposimeter was standing alone and was, thus, not worn by children or adults and therefore no consent of parents was needed and no influence due to shielding by the body was present, like when exposimeters are carried on the body. The interval between two measurements was minimized, so that a maximum number of measurement points were obtained over the week. During the measurement campaign the measurement cycle of each exposimeter (ES 140 and ES 121) was $30 \mathrm{sec}$ in Belgium 
and Greece. During one measurement cycle the exposimeter performs a measurement in all its frequency bands. The aim of these exposimeter measurements was to obtain the time-evolution for the different RF signals in typical indoor microenvironments and environments.

\section{Spatial measurements}

After starting the exposimeter measurement, a broadband measurement was performed in the room to locate the spot or area of maximum exposure. The location of highest exposure was identified through sweeping the area at a height of $1.5 \mathrm{~m}$ above floor level with a broadband probe. This is a typical height to characterize human exposure (ECC, 2004; CENELEC, 2008). This height can be seen as a worst-case assessment, where mainly the head region of children is considered (CENELEC, 2008). The Narda NBM-550 combined with an EF0391 probe and PMM-EP330 were used for these measurements in Greece and Belgium, respectively (Narda, Pfullingen, Germany).

The broadband measurements were followed by a frequency-selective measurement. In Belgium, the setup of the narrowband measurements consisted of tri-axial Rohde and Schwarz R\&S TS-EMF Isotropic Antennas (dynamic range of $1 \mathrm{mV} / \mathrm{m}$ $100 \mathrm{~V} / \mathrm{m}$ for the frequency range of $80 \mathrm{MHz}-$ $3 \mathrm{GHz}$, and $2.5 \mathrm{mV} / \mathrm{m}-200 \mathrm{~V} / \mathrm{m}$ for the frequency range of $2 \mathrm{GHz}-6 \mathrm{GHz}$ ) in combination with a spectrum analyzer (SA) of type R\&S FSL6 (frequency range of $9 \mathrm{kHz}-6 \mathrm{GHz})(\mathrm{R} \& \mathrm{~S}$, Zaventem, Belgium). Optimal spectrum analyzer and equipment settings are discussed in Joseph et al. (2012). The measurement uncertainty is $\pm 3 \mathrm{~dB}$ for the considered setup (CENELEC 2008, Joseph et al. 2012). This uncertainty represents the expanded uncertainty evaluated using a confidence interval of $95 \%$. In Greece, the selective radiation meter SRM-3000 (Narda, Pfullingen, Germany) was used along with a triaxial antenna (3501/01). This setup allows isotropic measurements from $75 \mathrm{MHz}$ to $3 \mathrm{GHz}$ with a dynamic range from $0.25 \mathrm{mV} / \mathrm{m}$ to $200 \mathrm{~V} / \mathrm{m}$. The extended isotropic measurement uncertainty (when operating in environment temperature from $+15^{\circ} \mathrm{C}$ to $+30^{\circ} \mathrm{C}$ ) varies for different frequency bands. The highest uncertainty values are observed in the $2701-3000 \mathrm{MHz}$ band and are +3.2 / -5.3 dB (SRM-3000 2013).
The narrowband measurements are used to assess the electric-field strength from $80 \mathrm{MHz}$ up to $3 \mathrm{GHz}$. These measurements were performed at two positions per room: at the position of maximal exposure (indicated with the broadband probe) and near the position where the personal exposimeter was placed. When no position of maximum exposure could be identified with the broadband probe, narrowband measurements were performed at the middle of the room. During the measurements the triaxial probe was positioned at a height of $1.5 \mathrm{~m}$. In Greece, eleven (11) narrowband measurements were performed according to the methodology published by Bürgi et al. (2010). The eleventh measurement at the position of maximal exposure as indicated with the broadband probe. When no such position could be identified then the maximum was assumed to be next to the window. The duration of measurements per location was between 20 to 70 minutes (less in Belgium and more in Greece, due to the increased number of measurement points at a location).

\section{Data analysis}

\section{Analysis of present RF signals}

To quantify the presence of RF sources in different environments, a factor $\mathrm{n}(\%)$ is defined. $\mathrm{n}$ represents the percentage of occurrence of an RF source above the detection limit of the spectral equipment in a microenvironment with respect to the total number of considered measurement positions in this microenvironment. $\mathrm{n}$ is derived from the narrowband measurements. A signal is considered as present if its level is larger than the sensitivity of the frequency-selective measurement setup. The sensitivity level varies with frequency and depends on the settings of the spectrum analyzer and the characteristics of the tri-axial probe. In Joseph et al. (2012) the sensitivities for the present signals are discussed; these range from $0.002 \mathrm{~V} / \mathrm{m}$ for TETRA/GSM900 to $0.009 \mathrm{~V} / \mathrm{m}$ for DAB (Table 3 in Joseph et al. (2012)). The sensitivity of the SRM-3000 varies also with frequency and can be found in (SRM-3000 2013): from $75 \mathrm{MHz}$ to $3 \mathrm{GHz}$, the sensitivity is $0.25 \mathrm{mV} / \mathrm{m}$ for triaxial use and $90 \mu \mathrm{V} / \mathrm{m}$ for single axis use. 


\section{Temporal analysis}

The temporal measurements aim at characterizing the time evolution of the RF signals during a day in terms of summary statistics, i.e., percentile values $\mathrm{p}_{\mathrm{x}}$ (where $\mathrm{x}$ denotes the percentile value). These measurements were performed with exposimeters. To reduce instantaneous variations of a signal and to emphasize the trend of a signal during a longer time period, an averaging method was applied on the dataset. According to international exposure guidelines, two averaging periods were considered, i.e., 6-min (ICNIRP 1998) and 30-min period (FCC 2001). Since a large proportion of the exposimeter measurements was censored, i.e., below the lower detection limit of the exposimeter, the robust regression on order statistics (ROS) method was applied to determine the summary statistics of the power density $\mathrm{S}\left(\mu \mathrm{W} / \mathrm{cm}^{2}\right)$ for each $30 \mathrm{~min}$ interval (95th percentile values) (Röösli et al., 2008, Helsel et al., 2005). To apply ROS the following condition has to be met: a minimum number of 50 samples and this for 24 hours (statistically relevant amount of samples (Lee, 1993)) has to be found above the lower detection limit of the exposimeter. ROS provides appropriate results even if the proportion of nondetects is larger than $80 \%$ (Röösli et al. 2008). Röösli et al (2008) performed ROS if at least three values per week were above the detection limit. Finally, the time course of field values in several days were averaged and normalized to determine the evolution per 24 hours for each RF signal. Total exposure $\mathrm{S}_{\text {tot }}\left(\mu \mathrm{W} / \mathrm{cm}^{2}\right)$ was determined by summing up the power density values of all downlink frequency bands. Values lower than the detection limit were omitted to determine the total exposure.

\section{Extrapolation to determine maximal electric-fields using exposimeter data}

On the one hand, exposure varies with time due to changes in the network load and environmental changes (i.e., fading). On the other hand, exposure is mostly measured at a particular point in time using a frequency-selective measurement setup. These are typically designated as spot measurements. Estimating maximal exposure, thus, requires the knowledge of the time evolution of the exposure. In this study, the time evolution was measured by exposimeters. We calculated the summary statistics of the electric field recorded by the exposimeter - after applying robust ROS to cope with nondetects - in 30 minute intervals. In every time interval a scale factor sf of an RF signal was defined as the ratio of the selected percentile value of the electric field strength of the RF signal and the maximum percentile value of the field strength over a complete day, i.e., 24 hours.

$$
s f(T)=\frac{E_{X}(T)}{\max _{T=0 \ldots 24 h}\left(E_{X}(T)\right)} \quad(-)
$$

with $E_{X}$ the $X^{\text {th }}$ percentile of the electric-field strength of an RF signal (FM, TV, GSM, UMTS, etc.) measured with the exposimeter in the time interval $\mathrm{T}(30 \mathrm{~min})$, and $\max ($.$) the maximum value$ over the time interval $\mathrm{T}$. The scale factor is a measure for the daily variation of the RF-EMF exposure.

The maximal exposure or electric-field value of a certain signal was estimated from the narrowband measurements $\mathrm{E}_{\mathrm{SA}}$ performed during a time interval $\mathrm{T}_{0}$ and $\mathrm{sf}$ in the same time interval:

$$
E_{\max }^{\mathrm{calc}}=E_{\mathrm{SA}}\left(T_{0}\right) \times\left(1 / s f\left(T_{0}\right)\right) \quad(V / m)
$$

with $\operatorname{sf}\left(\mathrm{T}_{0}\right)$ the scale factor of an RF signal at the time interval $\mathrm{T}_{0}$ when the frequency-selective measurements were performed.

The temporal variation var of a signal $\mathrm{X}$ is defined as the relative maximal deviation of the scale factor sf:

$$
v a r^{x}=100 \times \frac{\max \left(s f^{x}\right)-\min \left(s f^{x}\right)}{\max \left(s f^{x}\right)}
$$

with max and min the maximal and minimal value of the scale factors for an RF signal. Finally, the average variation var $_{\mathrm{avg}}$ of an $\mathrm{RF}$ signal per indoor microenvironment was used for the comparison of variations of different exposures.

\section{Results}

\section{Spatial narrowband measurements}

\section{Present RF sources}

Figures 1(a) and (b) show the presence of a signal (n in \%) per indoor microenvironment in Belgium 


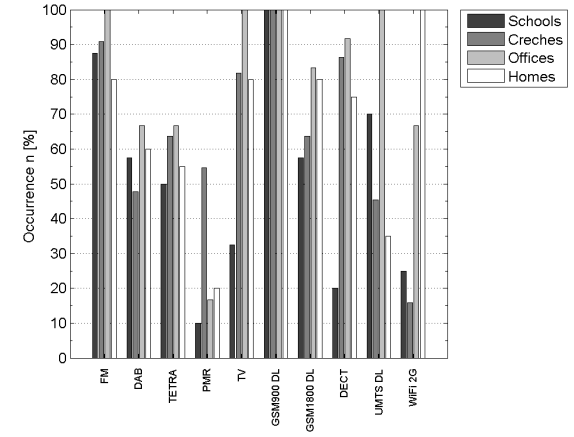

(a)

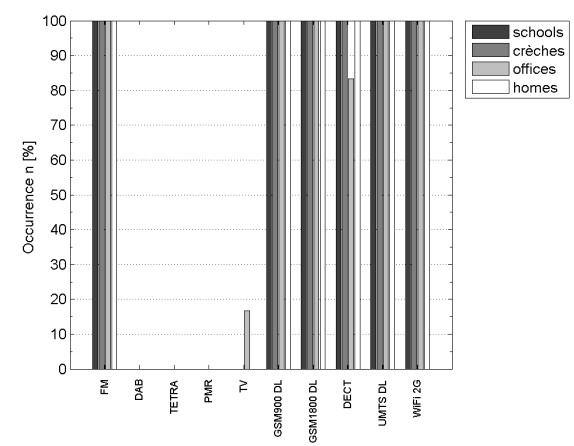

(b)

Figure 1: Percentage of the occurrence of various RF signals at different microenvironments in (a) Belgium and (b) Greece (narrowband measurements: sensitivities range from $0.002 \mathrm{~V} / \mathrm{m}$ for TETRA/GSM900 to $0.009 \mathrm{~V} / \mathrm{m}$ for DAB and are $0.25 \mathrm{mV} / \mathrm{m}$ for the SRM-3000).

and in Greece, respectively. In Belgium, exposures of the ten following RF signals were determined, namely FM, DAB, TETRA, PMR, TV, GSM900 DL, GSM1800 DL, DECT, UMTS DL and WiFi 2G (abbreviations, see Table 2). Compared to Belgium, DAB, TETRA; and PMR were not measured in Greece. The other signals were omnipresent in Greece except for DECT in offices and digital TV. In Belgium only GSM900 DL was measured at every position.

In Belgium, DECT was mainly encountered in creches, offices, and homes $(\geq 75 \%)$ and less frequently in schools (20\%). Besides DECT, WiFi 2G was also frequently measured in indoor microen- vironments. In Greece, WiFi $2 \mathrm{G}$ was measured at all indoor locations whereas in Belgium WiFi $2 \mathrm{G}$ was mainly encountered in offices (omnipresent) and homes $(>65 \%)$. In schools and creches, WiFi $2 \mathrm{G}$ was less available $(\leq 25 \%)$ in Belgium.

Considering only the broadcasting signals (FM, DAB, and digital TV), FM ( $\geq 80 \%$ ) was the most observed, followed by digital TV and DAB (presence between $30 \%$ and $100 \%$ ).

\section{Total RF exposure for the different indoor environments}

Table 3 summarizes the narrowband measurements, performed in Belgium and in Greece, for the considered indoor microenvironments: the maximum $\left(\mathrm{E}_{\max }\right)$, average $\left(\mathrm{E}_{\mathrm{avg}}\right)$, and the standard deviation (std) of electric-field strengths per RF signal.

All measured electric-field strengths satisfied the ICNIRP guidelines for general public (ICNIRP, 1998). In Belgium, the highest maximal total (cumulative) field value was measured in an office and equals $3.6 \mathrm{~V} / \mathrm{m}$. This value is 10 times below the ICNIRP reference levels and mainly due to the line-of-sight (LOS) path of a nearby TV transmitter $(3.5 \mathrm{~V} / \mathrm{m}$, i.e., Digital Video BroadcastingTerrestrial (DVB-T) or digital TV). The lowest maximal total field value was measured in homes $(0.8 \mathrm{~V} / \mathrm{m})$. In schools and crèches, the maximal total field value equaled $1.6 \mathrm{~V} / \mathrm{m}$ and $1.2 \mathrm{~V} / \mathrm{m}$, respectively. In Greece, the highest maximal total field value was caused by DECT in homes and equaled $2.1 \mathrm{~V} / \mathrm{m}, 29$ times below the ICNIRP reference levels. The lowest maximal total field value was measured in offices $(1.1 \mathrm{~V} / \mathrm{m})$. In schools and crèches, the maximal total field value equaled $1.7 \mathrm{~V} / \mathrm{m}$ and $1.6 \mathrm{~V} / \mathrm{m}$, respectively.

Considering average exposures, FM and GSM900 DL dominated $($ Eavg $=0.3 \mathrm{~V} / \mathrm{m}$ and $0.2 \mathrm{~V} / \mathrm{m}$, Table 3) in Belgian schools, while in Greece the dominating signal in schools was GSM1800 DL $(0.3 \mathrm{~V} / \mathrm{m})$. The highest average field values in creches were measured for GSM900 DL (Eavg = $0.2 \mathrm{~V} / \mathrm{m}$ ) and for FM in Greece (Eavg $=0.3 \mathrm{~V} / \mathrm{m})$. In offices, the TV signal dominated (Eavg $=0.8$ $\mathrm{V} / \mathrm{m}$ ). Furthermore, average field values were obtained of $0.3 \mathrm{~V} / \mathrm{m}$ for GSM900 DL in both countries. For GSM1800 DL and UMTS DL higher average values were obtained in Greece. In Belgium 
Table 2: Description and characteristics of the frequency band measured by the exposimeters and the proportion of measurements above the detection limit.

\begin{tabular}{|c|c|c|c|c|}
\hline \multirow[t]{2}{*}{ Band } & \multirow[t]{2}{*}{ Frequency $(\mathrm{MHz})$} & \multirow[t]{2}{*}{ Detection limit $(\mathrm{V} / \mathrm{m})$} & \multicolumn{2}{|c|}{$\begin{array}{l}\text { Proportion of meas. above } \\
\text { detection limit }(\%)\end{array}$} \\
\hline & & & Belgium & Greece \\
\hline FM & $88-108$ & 0.050 & 18 & 49 \\
\hline $\mathrm{DAB}$ & $174-223$ & 0.020 & 21 & 20 \\
\hline TETRA & $380-400$ & 0.010 & 5 & 3 \\
\hline DVB-T/TV & $470-830$ & 0.010 & 45 & 44 \\
\hline GSM900 UL & $880-915$ & 0.005 & 4 & 29 \\
\hline GSM900 DL & $925-960$ & 0.005 & 90 & 55 \\
\hline GSM1800 UL & $1710-1785$ & 0.005 & 25 & 27 \\
\hline GSM1800 DL & $1805-1880$ & 0.005 & 57 & 56 \\
\hline DECT & $1880-1900$ & 0.005 & 54 & 61 \\
\hline UMTS UL & $1920-1980$ & 0.005 & 2 & 7 \\
\hline UMTS DL & $2110-2170$ & 0.005 & 51 & 47 \\
\hline WIFI $2 \mathrm{G}$ & $2400-2500$ & 0.005 & 24 & 42 \\
\hline
\end{tabular}

$\mathrm{FM}=$ frequency modulation, DAB = Digital Audio Broadcasting, DECT = Digital Enhanced Cordless

Telecommunications, DL = downlink i.e., communication from base station to mobile phone, GSM = Global System for Mobile Communications, GSM900 = GSM at $900 \mathrm{MHz}$, GSM $1800=$ GSM at $1800 \mathrm{MHz}$, PMR = Personal mobile Radio, TETRA = Terrestrial Trunked Radio, TV = television, UMTS = Universal Mobile Telecommunications

System, UL = uplink i.e., communication from mobile phone to base station, WiFi $2 \mathrm{G}=$ wireless ethernet for Wireless

Local Area Networks at $2.4 \mathrm{GHz}$

DECT and $\mathrm{WiFi} 2 \mathrm{G}$ were on average $0.2 \mathrm{~V} / \mathrm{m}$. The highest average field values in homes were due to the DECT signal and equaled $0.2 \mathrm{~V} / \mathrm{m}$ and $0.3 \mathrm{~V} / \mathrm{m}$ in Belgium and Greece, respectively.

In Belgium, higher values were measured for GSM DL at $900 \mathrm{MHz}$ and $1800 \mathrm{MHz}$ than for the more recent telecommunication signal UMTS DL in all microenvironments. In Greece, average field levels of GSM DL and UMTS DL were comparable (about $0.06 \mathrm{~V} / \mathrm{m}$ ).

Figure 2 shows the empirical cumulative distribution functions (cdf) of the total exposures (cumulative of all RF signals) for the different (indoor) environments in Belgium ((a) and (b)) and in Greece ((c) and (d)). In both countries, exposure depended on the environment and increased with increasing population density (Figures 2(c) and (d). In more dense environments exposure was typically higher because more RF signals were present in these environments. With respect to the type of indoor microenvironment, no significant differences are observed in Belgium (Figure 2(a)), whereas in Greece the highest exposure was meaured in offices followed by creches and homes, and schools. In one
Belgian office, total exposures were strongly dominated by the TV signal. This value is omitted from the CDF to enable visual comparison (Figures 2(a) and $(b))$.

\section{Power density contributions per indoor en- vironment}

Figure 3 shows the average contribution (AC) of the power density (in \%) of each signal to that of the total signal per indoor microenvironment in Belgium (a) and Greece (b).

Downlink signals from mobile communications systems (Greece GSM1800: up to $25.6 \%$ on average, Belgium GSM900: up to $36.6 \%$ on average) and from indoor systems (Greece WiFi 2G: up to $30.1 \%$ on average, Belgium DECT: up to $36.2 \%$ on average) contributed the most to the total exposure. The GSM900 DL signal contributed in Belgium on average more than $20 \%$ to the total value at every location. The GSM1800 DL and UMTS DL signals contributed less than GSM900: their contributions were lower than $5 \%$ in every environment. 


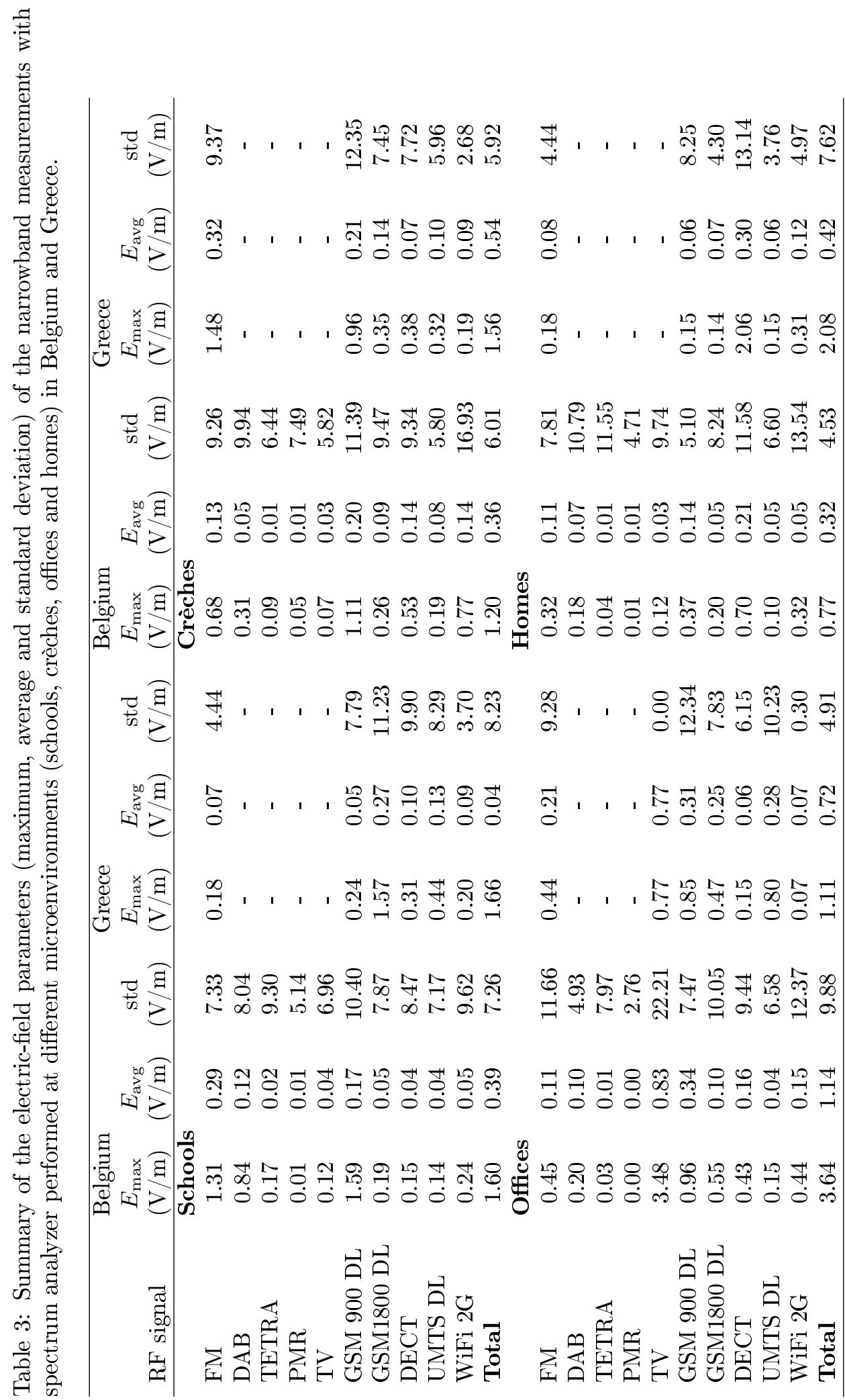




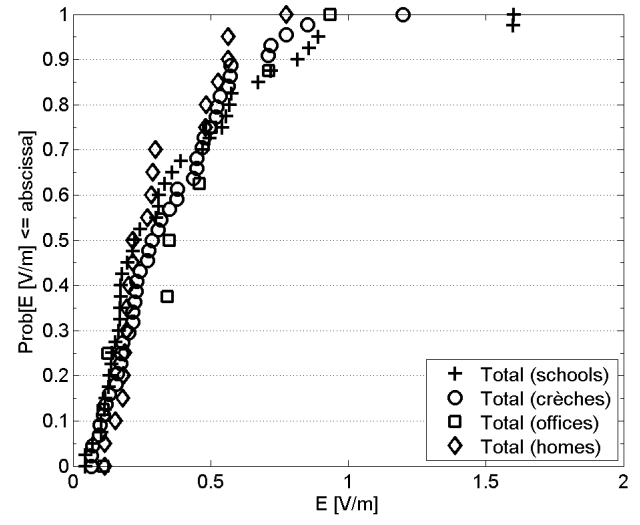

(a)

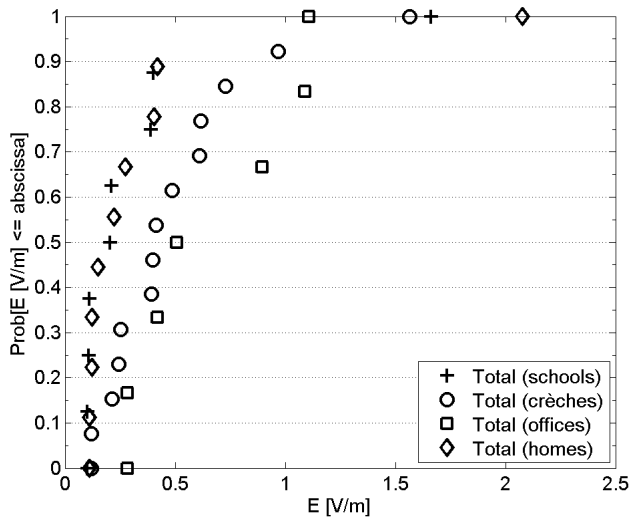

(c)

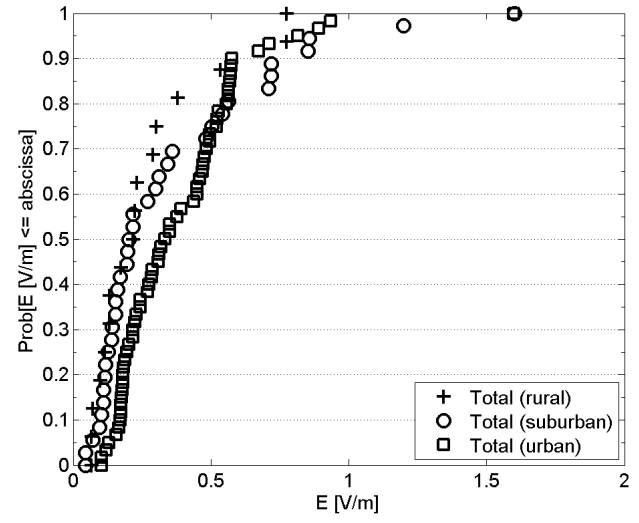

(b)

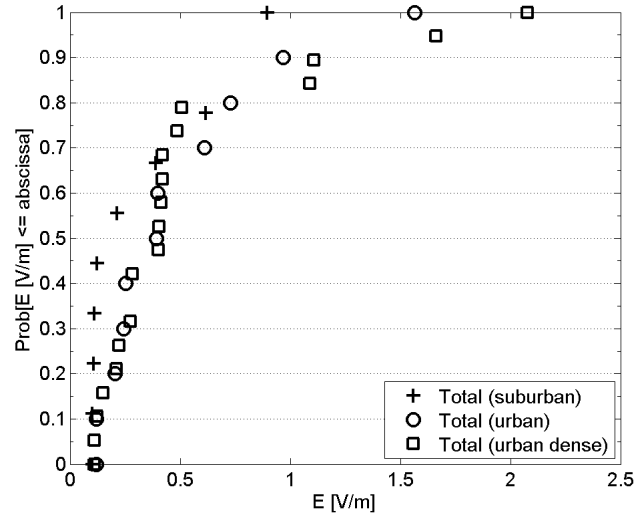

(d)

Figure 2: Cumulative distribution function (CDF) of total exposure for different microenvironments and different environments in Belgium (a), (b) and in Greece (c), (d) (maximal value in one Belgian office is omitted to avoid skewing of the distribution and enable visual comparison). 
In homes, the main contributions to the total field were due to indoor sources: DECT contributed in Belgium on average for $36.2 \%$ and in Greece for $28.2 \%$. In Belgium average contributions for DECT were significantly lower in schools $(4.4 \%)$ compared to other indoor environments: the DECT base stations were only occasionally encountered in schools where they are placed in the corridors.

Higher average contributions for $\mathrm{WiFi} 2 \mathrm{G}$ were produced in Belgian office (13.6\%) and home $(6.7 \%)$ environments. In other indoor environments WiFi 2G contributed less than $5 \%$. On the contrary, in Greece WiFi $2 \mathrm{G}$ contributed the most in home $(30.1 \%)$ environments.

For the broadcast signals, the main contribution in all indoor environments was due to FM (up to $58.3 \%$ in Belgium and $43.0 \%$ in Greece), except for $\mathrm{TV}$ in Belgian offices $(32.0 \%)$. In Belgium at every location average contributions for TETRA and PMR are limited to $0.4 \%$.

\section{Temporal measurements}

\section{Time evolution of exposures}

To visualize the temporal exposures, the timeevolution of each signal, obtained in the same microenvironment, were averaged per time-interval of $30 \mathrm{~min}$ and normalized to the maximum value. Figure 4 shows the time evolution of the total signals during 24 hours for the different indoor microenvironments in Belgium (Figure 4(a)) and Greece (Figure 4(b)). In addition, Figure 5 shows the course of GSM900 DL, which is still the dominating telecom signal.

In all indoor environments main temporal variations are due to mobile telecommunication signals as these dominate total exposures. In offices, the time-evolution of the total signal is also influenced by TV signals (next to the telecom signals) and in crèches (Belgium) and homes by indoor signals (DECT and WiFi 2G).

Daily exposure variations are also clear from Figures 4 and 5. Highest values for the total exposure (sf closest to 1 in Figure 4) were obtained around noon in offices (10 am $-4 \mathrm{pm})$, whereas in homes highest values occured in the evening $(8 \mathrm{pm}$ $-12 \mathrm{pm}$ ) due to indoor signals and the use of mobile phones at home. For schools and crèches in
Belgium and Greece different time-evolutions were found: in Belgian schools and in Greek crèches maximal exposure occured in the late afternoon $(5 \mathrm{pm}-9 \mathrm{pm})$, and in Belgian crèches and in Greek schools highest values were obtained around noon $(10 \mathrm{am}-2 \mathrm{pm})$. Figures 5(a) and (b) show that exposure to GSM900 DL increased at two time instants during the day, namely around $9 \mathrm{am}-2 \mathrm{pm}$ and around $4 \mathrm{pm}-9 \mathrm{pm}$.

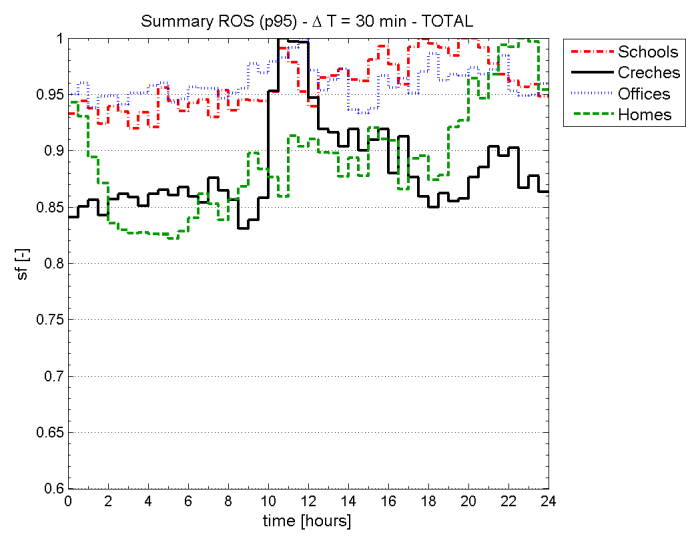

(a)

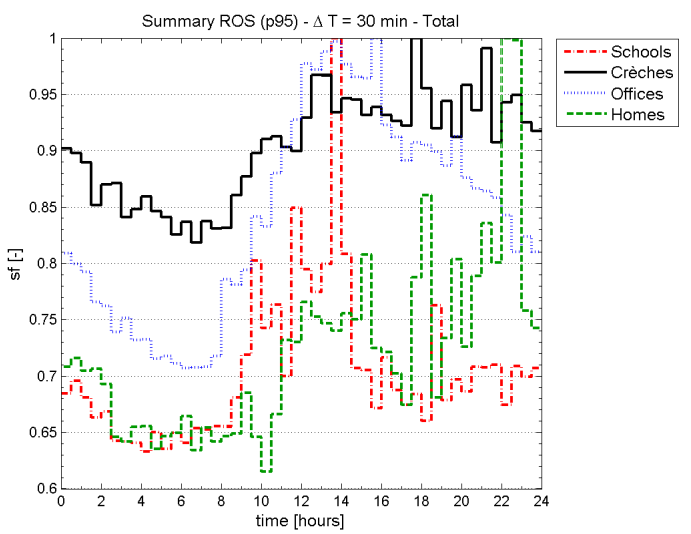

(b)

Figure 4: Temporal variations (scale-factor) over 24 hours of total signals in schools, crèches, offices and homes in (a) Belgium and (b) Greece (time in absolute hours: e.g., "0" hour means midnight). 


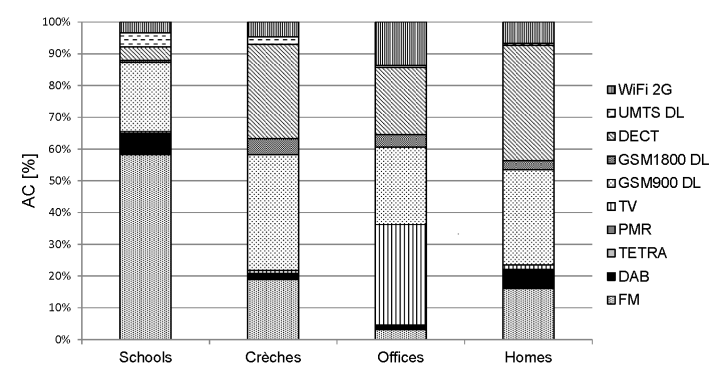

(a)

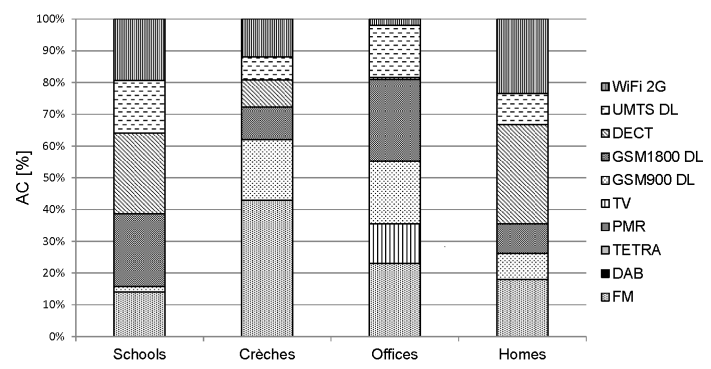

(b)

Figure 3: Average contribution (AC) of various RF signals at different microenvironments (schools, crèches, offices and homes) in (a) Belgium and (b) Greece.

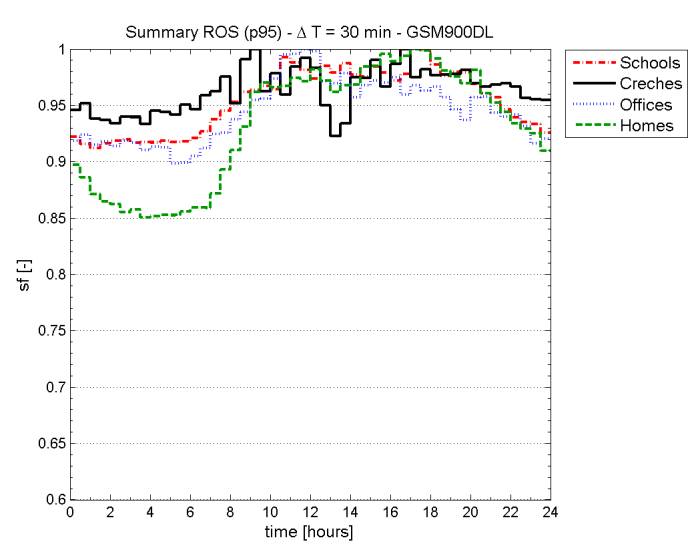

(a)

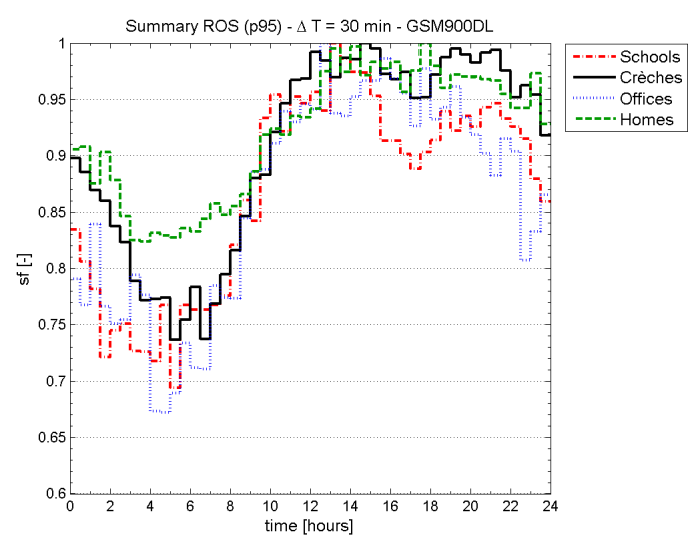

(b)

Figure 5: Temporal variations (scale-factor) over 24 hours of GSM900 telecommunication signals in schools, crèches, offices and homes in (a) Belgium and (b) Greece.
Table 2 provides the proportions of measurements above the detection limit of the exposimeter for each frequency band in Belgium and Greece. Except for GSM900 UL, the percentages in both countries agreed well. Proportions ranged from $3 \%$ (TETRA, Greece) to $90 \%$ (GSM900 DL, Belgium).

Figures 6(a) and (b) show the average variations of the temporal evolution per signal and per indoor microenvironment in Belgium and in Greece, respectively. Also the variations for the total (cumulative) exposure (denoted as "total") are presented. Highest total variations (varavg) in Belgium occured in crèches $(39.3 \%)$, followed by homes $(31.2 \%)$, schools $(24.6 \%)$ and offices $(14.6 \%)$, whereas in Greece highest total variations (varavg) occured in homes $(58.2 \%$ ), followed by schools $(49.6 \%)$, offices $(41.2 \%)$ and crèches $(37.5 \%)$. Highest variations in Belgium were obtained for $\mathrm{DAB}$ (schools), and WiFi 2G (crèches) and in Greece for DECT (crèches and homes), UMTS DL (schools) and WiFi 2G (offices).

For the broadcast signals, highest variations were obtained for the DAB signal $(49.4 \%)$ in Belgian schools and for the TV signal $(37.0 \%)$ in Greek offices. In both countries, variations for FM are in general lower than for the telecommunication signals (UMTS). The use of data communication within UMTS-HSDPA networks can cause high variations of the field values (Mahfouz et al., 2011).

For indoor signals, variations higher than $30 \%$ occurred for DECT and WiFi $2 \mathrm{G}$ except for DECT $(27.2 \%)$ in Belgian offices and WiFi 2G (12.1\%) in Greek schools. 


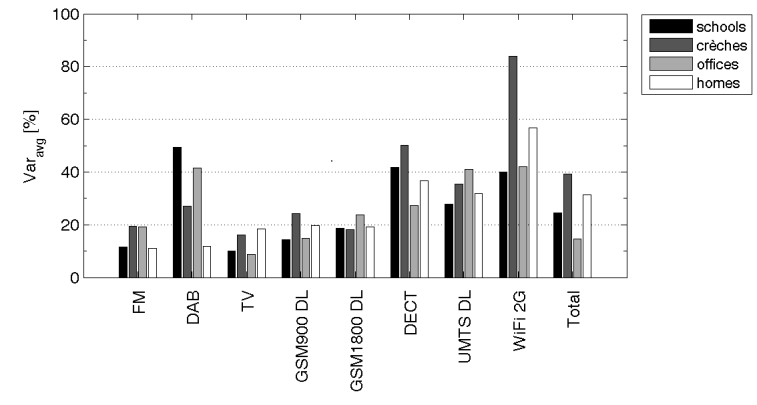

(a)

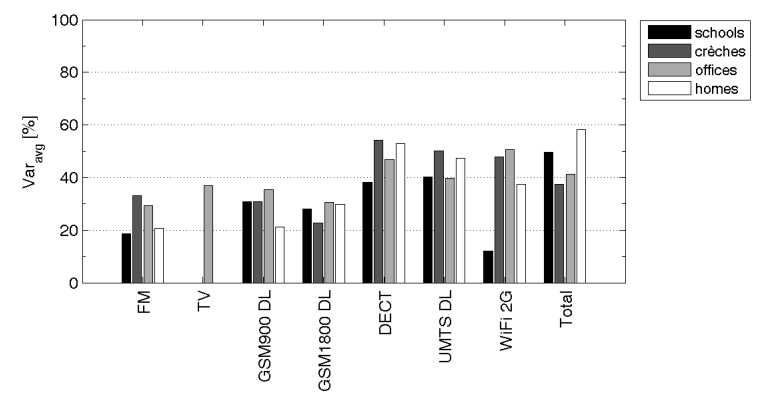

(b)

Figure 6: Average variation (varavg) of timeevolution for various RF signals at different microenvironments in (a) Belgium and (b) Greece (TETRA in Belgium and Greece and DAB in Greece are not shown because of insufficient data).

\section{Estimation of maximal exposure using tem- poral data and validation}

To obtain the maximal electric-field value instantaneous narrowband measurements are multiplied with the inverse of the scale factor at the time instant of the narrowband measurement. Figures 7 (a) and (b) present the maximum estimated field values of different signals per indoor microenvironment in Belgium and in Greece, respectively. After applying the corresponding scale factor to the instantaneous narrowband measurements, the obtained electric-field strengths still satisfy the ICNIRP guidelines. The standard deviations, average, and maximal measured field values used for the extrapolation are provided in Table 3 .

This extrapolation approach is validated by performing continuously narrowband measurements

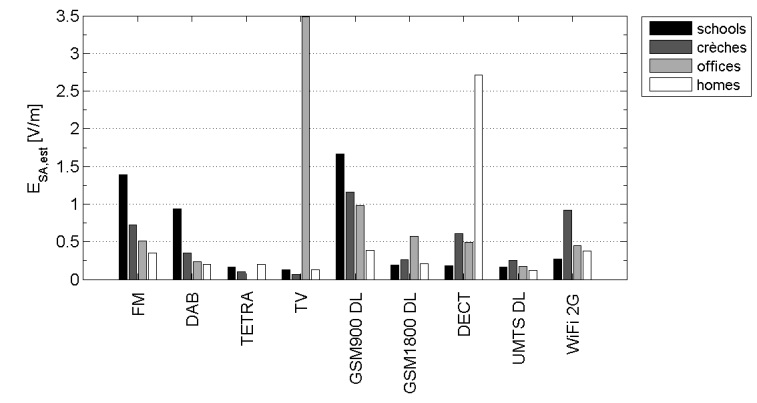

(a)

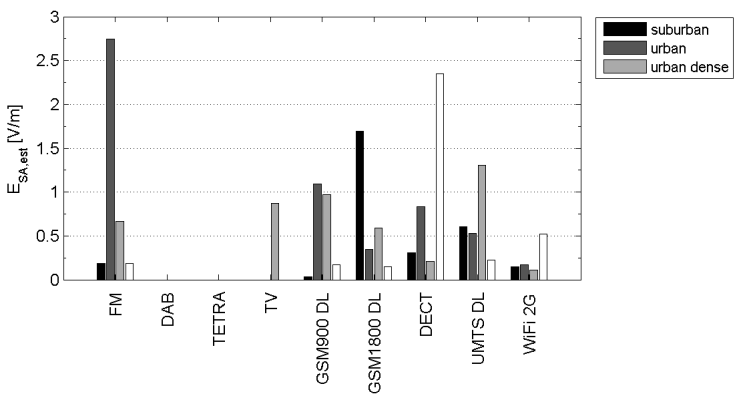

(b)

Figure 7: Maximum extrapolated electric-field strengths of the instantaneous narrowband measurements performed at different microenvironments in (a) Belgium and in (b) Greece.

in parallel with temporal exposimeter measurements. The narrowband measurements were processed identically as the exposimeter measurements (i.e., 95th percentile value for each 30-min interval). On average, relative deviations of $30.0 \%$ were obtained for GSM900 DL and $17.1 \%$ for UMTS DL in Belgium. These deviations are acceptable when considering the measurement uncertainty of the narrowband setup and the exposimeters (Section 2.2).

\section{Discussion}

\section{Strength and limitations}

This paper is the first one to assess both spatial and temporal exposure for indoor environments where children reside. Our study offers a comparison of RF-EMF exposure in schools, crèches, homes, and 
offices. Few literature was available about (child and adult) exposure in indoor microenvironments.

A method to assess spatial and temporal indoor exposure of children and adults was proposed without involving any human subjects in the measurements. Maximal daily exposure was assessed by combining instantaneous spatial exposure and temporal data. This extrapolation approach was validated in Belgium and Greece. Derived exposures are proxies for instantaneous and maximal child and adult exposure in indoor environments during a day.

The measurements in the two countries occurred following a joint protocol namely, broadband measurements, followed by narrowband measurements and temporal measurements with exposimeters. The settings of the equipment were exactly the same. So, study design was performed jointly and similar. There were some differences (e.g., in Greece, 7 additional narrowband measurements were performed in the middle of the room) but these were not considered in this study.

The exposimeters were placed at various positions in the investigated rooms and were standing alone. They were thus not worn by children or adults and therefore, no consent of parents was needed. Also no influence due to shielding occured, like when exposimeters are carried on the body (underestimations up to $6.5 \mathrm{~dB}$ are possible according to Iskra et al. (2010)).

However, limitations still exist. Changing the batteries of the exposimeters can cause incorrect fluctuations of the electric-field strength. Therefore, to eliminate those fluctuations, data samples were grouped in measurement periods that correspond to one set of batteries. Then the data samples were normalized per measurement period. Another limitation is that some of the results are based on only a limited number of different indoor microenvironments. For example for offices, the mean values in Greece and Belgium are based on only 5 and 3 offices, respectively. Such results may thus not be representative for the whole study area.

\section{Interpretation}

Mobile telecommunications were present in all environments together with radio broadcasting, as reported in Joseph et al. (2010) and Frei et al. (2009). Except for classrooms of schools in Bel- gium, DECT was present at $75 \%$ or more of the considered measurement positions. The highest values for DECT were measured in homes (Emax $=0.7 \mathrm{~V} / \mathrm{m}$ ) and the lowest values in schools (Emax $=0.2 \mathrm{~V} / \mathrm{m}$ ). This can be explained mainly due to the fact that no DECT base stations were present in classrooms (in contrary to rooms at other indoor microenvironments).

In Belgium, higher values were measured for GSM (900 and 1800) than for the more recent telecommunication signal UMTS DL in all indoor microenvironments because in Belgium GSM is currently more used. In Greece this was not so clear. Comparing to Belgium, higher values for UMTS DL were found in all indoor microenvironments.

In Belgium, the high exposure of the TV (DVB$\mathrm{T})$ signal at an office was caused by the presence of line-of-sight TV antennas mounted on an opposite office building. In Greece, high values for FM and TV were obtained in suburban environments, because broadcasting antennas are located close to the areas where the suburban measurements were conducted.

Temporal data were divided into intervals of 30 minutes taking human exposure standards into account. In all indoor environments the timeevolution of the total signal during 24 hours was due to the dominating signals: this explains why temporal variations were mainly due to variations of mobile telecommunication signals. Besides these signals, variations in crèches were also caused by DECT and WiFi $2 \mathrm{G}$, while in offices variations were also caused by the broadcasted TV signal, which varies less and therefore results in lower variations of the total signal. In Belgian crèches, peak values were frequently measured with the exposimeters before noon. These peaks might be attributed to microwave ovens present in the considered rooms, and explain some of the the high variations for $\mathrm{WiFi}$ 2G (Figure 6(a)) and the higher total exposure before noon in crèches (Figure $5(\mathrm{a})$ ).

\section{Spatial exposure}

Highest exposures were found in urban environments and the lowest in rural environments. This agrees with the field distributions presented in Tomitsch et al. (2010) and Joseph et al. (2012). The median exposures of Joseph et al. (2012) $(0.1 \mathrm{~V} / \mathrm{m}$ for GSM900 DL, $0.04 \mathrm{~V} / \mathrm{m}$ for GSM1800 
DL, $0.03 \mathrm{~V} / \mathrm{m}$ for UMTS DL) are of the same order for those signals in the different indoor microenvironments considered here.

Exposures in schools and kindergartens were up to now only assessed in Juhász et al. (2011) and Khalid et al. (2011). Higher electric-field values due to $\mathrm{WiFi} 2 \mathrm{G}$ were also measured in kindergartens compared with the values obtained in schools (Juhász et al., 2011). However, this trend is explained by the contributions of microwave ovens present in kindergartens. Higher exposures in offices than in homes were also reported in Frei et al. (2009) and Joseph et al. (2010). Also similar contributions for TV $(30.3 \%$ versus here $31.6 \%$ in Belgian offices) and for GSM900 (28.7\%) were obtained.

Average DECT contributions obtained in this study are $36.2 \%$ in Belgian homes and $28.2 \%$ in Greek homes, and $21.1 \%$ in Belgian offices. This agrees well with DECT indoor average contributions of $28.9 \%$ in Joseph et al. (2012) and of $32.6 \%$ (homes) and $24.1 \%$ (offices) in Frei et al. (2009).

Finally, Tomitsch et al. (2010) measured exposures in bedrooms of residences. The values reported here (on average total exposures of $0.32 \mathrm{~V} / \mathrm{m}$ in Belgian homes and $0.43 \mathrm{~V} / \mathrm{m}$ in Greek homes, Table 3) are comparable with those of Tomitsch et al. (2010) where median values in bedrooms of houses of $40.3 \mu \mathrm{W} / \mathrm{m} 2(0.12 \mathrm{~V} / \mathrm{m})$ for the RF frequency range, were obtained. The majority of the houses in Tomitsch et al. (2010) were located in rural areas (154 of the 226 houses), explaining the slightly lower average exposures than in this study. Tomitsch et al. (2010) also reported higher values due to mobile telecom signals and DECT.

\section{Temporal exposure}

Existing literature and procedures about temporal exposure is scarce. In Joseph et al. (2009), Joseph and Verloock (2010), and Manassas et al. (2012) higher field values were found for telecommunication signals during daytime than at night due to the presence of traffic. This can also be seen from the time-evolution obtained in this study (Figures 4 and 5). Daily variations are due to mobile telecommunications and can be attributed to the operation of mobile phone networks, which causes day and night fluctuations in the electric field (Joseph and Verloock 2010; Mahfouz et al., 2011; Manassas et al., 2012). Manassas et al. (2012) investigated diurnal variations of fields due to broadcasting and mobile telecommunication and provided median variations of $20.2 \%$ and $33.8 \%$ for broadcast signals and telecommunication signals, respectively. Variations of the same order (on average for total exposures up to $40 \%$ in crèches, Figure 6) were found in our study. In Joseph and Verloock (2010), Erlang data (representing average mobile phone traffic intensity during a period of time) was related to RF exposure using temporal measurements during a week. Mahfouz et al. (2011) compared real exposure with the maximal estimated exposure to characterize the ratio between daily and maximum theoretical exposures. Based upon the traffic variation during 1 day, a general mask was found for GSM900, GSM1800, UMTS, and HSDPA, showing periods of little traffic or low-traffic hours (1 am $6 \mathrm{am})$ and rush hours $(12 \mathrm{pm}-2 \mathrm{pm}$ and $5 \mathrm{pm}-$ $9 \mathrm{pm})$. The time-evolution for GSM900 DL in different indoor environments (Figure 5) agrees well with this general mask.

\section{Conclusions}

Our study assessed spatial and temporal RF exposure at typical indoor microenvironments (schools, crèches, offices and homes) in Belgium and Greece. Furthermore, a method was presented to extrapolate instantaneous exposure to maximal daily exposure, combining spatial field values and 24 hour time-evolution of the electric fields. It was found that all instantaneous and maximal exposures satisfied international exposure limits. Mobile telecommunications were most present in all indoor microenvironments together with radio broadcasting (FM). In both countries, highest average exposures were found in office environments $(1.1 \mathrm{~V} / \mathrm{m}$ in Belgium and $0.7 \mathrm{~V} / \mathrm{m}$ in Greece) and lowest in homes $(0.3 \mathrm{~V} / \mathrm{m}$ in Belgium and $0.4 \mathrm{~V} / \mathrm{m}$ in Greece) and in schools $(0.4 \mathrm{~V} / \mathrm{m}$ in Greece). Exposure in offices was mainly due to mobile telecommunications whereas in home environments, DECT and $\mathrm{WiFi}$ $2 \mathrm{G}$ were the dominating sources. In homes, the average contribution to the total electric-field values was more than $28 \%$ for DECT and $6.7 \%$ (Belgium) and $30.1 \%$ (Greece) for WiFi 2G. Highest electricfield values were obtained in urban environments and lowest in rural environments. Concerning the 
temporal measurements, the time-evolution of the total signal over 24 hours is mainly due variations of mobile telecommunication signals in all indoor microenvironments. In offices, the time evolution of the total signal is also influenced by TV signals; in crèches (Belgium) and homes by indoor signals (DECT and WiFi 2G). Variations of the total signal are highest in Belgian crèches $(39.3 \%)$ and in Greek homes (58.2\%).

\section{Acknowledgments}

W. Joseph is a Post-Doctoral Fellow of the FWO-V (Research Foundation-Flanders).

\section{References}

Bürgi, A., Frei, P., Theis, G., Mohler, E., BraunFahrländer, C., Fröhlich, J., Neubauer, G., Egger, M., Röösli, M., 2010. A Model for Radiofrequency Electromagnetic Field Predictions at Outdoor and Indoor Locations in the Context of Epidemiological Research. Bioelectromagnetics 31, 226-236.

CENELEC European Committee for Electrotechnical Standardisation TC 106x WG1 EN 50492 in situ. 2008. Basic standard for the in-situ measurement of electromagnetic field strength related to human exposure in the vicinity of base stations.

Electronic Communications Committee (ECC). 2004. Electronic Communications Committee within the European Conference of Postal and Telecommunications Administrations (CEPT), ECC recommendation (02)04 (revised Bratislava 2003, Helsinki 2007) Measuring non-ionising electromagnetic radiation $(9 \mathrm{kHz}-300 \mathrm{GHz})$. Online: http://www.ero.dk (Last accessed 4 April 2013).

Federal Communications Commission (FCC), 2001. Evaluating Compliance with FCC Guidelines for Human Exposure to Radiofrequency Electromagnetic Fields. Washington, DC, Tech. Rep. Suppl. C to OET Bulletin 65.
Frei, P., Mohler, E., Neubauer, G. Theis, G., Burgi, A., Frohlich, J., Braun-Fahrlander, C., Bolte, J., Egger, M., Roösli, M., 2009, Temporal and spatial variability of personal exposure to radiofrequency electromagnetic fields. Environmental Research. 109, 779-785.

Helsel, D.R., 2005. In: Scott M, Barnett V, editors. Nondetects and data analysis. John Wiley \& Sons Inc, New Jersey.

International Commission on Non-ionizing Radiation Protection (ICNIRP), 1998. Guidelines for limiting exposure to time-varying electric, magnetic, and electromagnetic fields (up to $300 \mathrm{GHz}$ ). Health Phys 74(4), 494-522.

Iskra, S., McKenzie, R.. Cosic, I., 2010. Factors influencing uncertainty in measurement of electric fields close to the body in personal RF dosimetry. Radiat Prot Dosimetry. 140(1), 2533 .

Joseph, W., Vermeeren, G., Verloock, L., Heredia, M.M., Martens, L., 2008. Characterization of personal RF electromagnetic field exposure and actual absorption for the general public. Health Phys 95(3), 317-30.

Joseph, W., Verloock, L., Tanghe, E., Martens, L., 2009. In-situ measurement procedures for temporal RF electromagnetic field exposure of the general public. Health Phys 96(5), 529-542.

Joseph, W., Verloock, L., 2010. Influence of mobile phone traffic on general public base station exposure. Health Physics 99(5), 631-638.

Joseph, W., Frei, P., Roösli, M., Thuróczy, G., Gajsek, P., Trcek, T., Bolte, J., Vermeeren, G., Mohler, E., Juhasz, P., Finta, V., Martens, L., 2010. Comparison of personal radio frequency electromagnetic field exposure in different urban areas across Europe. Environmental Research 110(2010), 658-663.

Joseph, W., Verloock, L., Goeminne, F., Vermeeren, G., and Martens, L., 2012. Assessment of RF exposures from emerging wireless communication technologies in different environments. Health Physics 102(2), 161-72. 
Juhász, P., Bakos, J., Nagy, N., Jánossy, G., Finta, V., Thuróczy, G., 2011. RF personal exposimetry on employees of elementary schools, kindergartens and day nurseries as a proxy for child exposures. Progress in Biophysics and Molecular Biology. 107(3), 449-455.

Khalid, M., Mee, T., Peyman, A., Addison, D., Calderon, C., Maslanyj, M., Man, S., 2011. Exposure to radio frequency electromagnetic fields from wireless computer networks: Duty factors of Wi-Fi devices operating in schools. Progress in Biophysics and Molecular Biology 107 (3), 412-420.

Lee W. C., 1993. Mobile Communications Design Fundamentals: John Wiley \& Sons, Inc, New Jersey.

Mahfouz, Z., Gati, A., Lautru, D., Wong, M-F. Wiart, J., Hanna, VF., 2011. Influence of Traffic Variations on Exposure to Wireless Signals in Realistic Environments, Bioelectromagnetics. doi: 10.1002/bem.20705.

Mann, S., 2010. Assessing personal exposures to environmental radiofrequency electromagnetic fields. Comptes Rendus Physique: Interactions between radiofrequencies signals and living organisms 11(9-10), 541-555.

Manassas, A., Boursianis, A., Samaras, T., Sahalos, JN., 2012. Continuous electromagnetic radiation monitoring in the environment: analysis of the results in Greece. Radiat Prot Dosimetry. 151(3), 437-42.

Röösli, M., Frei, P., Mohler, E., Braun-Fahrländer, C., Burgi, A., Fröhlich, J., Neubauer, G., Theis, G., Egger, M., 2008. Statistical analysis of personal radiofrequency electromagnetic field measurements with nondetects. Bioelectromagnetics 29(6), 471-478.

Röösli, M., Frei, P., Bolte, J., Neubauer, G., Cardis, E., Feychting, M., Gajsek, P., Heinrich, S., Joseph, W., Mann, S., Martens, L. Mohler, E., Parslow, R., Poulsen, A.H., Radon, K., Schüz, J., Thuroczy, G., Viel, J.F., Vrijheid, M., 2010. Conduct of a personal radiofrequency electromagnetic field measurement study: proposed study protocol. Environmental Health 2010, 9:23.
SRM-3000, 2013. Technical specifications. www.rf-safety.com/pdfs/SRM3000.pdf, Narda-STS. Accessed on March 29, 2013.

Tomitsch, J., Dechant, E., Frank, W., 2010. Survey of Electromagnetic Field Exposure in Bedrooms of Residences in Lower Austria. Bioelectromagnetics (31), 200-208.

Thielens, A., De Clercq, H., Agneessens, S., Lecoutere, J., Verloock, L., Declercq, F., Vermeeren, G., Tanghe, E., Rogier, H., Puers, R., Martens, L., Joseph, W. 2013. Personal Distributed Exposimeter for Radio Frequency Exposure Assessment in Real Environments Bioelectromagnetics, doi: 10.1002/bem.21793.

Thuróczy, G., Molnár, F., Jánossy, G., Nagy, N., Kubinyi, G., Bakos, J., Szabó, J., 2008. Personal RF exposimetry in urban area, Ann Telecommun 63, 87-96.

Viel, J.-F., Cardis, E., Moissonnier, M., De Seze, R., Hours, M., 2009. Radiofrequency exposure in the French general population: Band, time, location and activity variability. Environ Int. $35(8), 1150-1154$. 